\title{
Outcome of Percutaneous Release for Trigger Digits in Diabetic and Non-diabetic Patients
}

\author{
Adeel A. Siddiqui ${ }^{1}$, Irfan Muhammad Rajput ${ }^{1}$, Mariyam Adeel ${ }^{2}$ \\ 1. Orthopaedic Surgery, Dow University of Health Sciences, Karachi, PAK 2. Orthopaedics, Dow \\ University of Health Sciences, Karachi, PAK
}

$\square$ Corresponding author: Adeel A. Siddiqui, zone4444@hotmail.com

Disclosures can be found in Additional Information at the end of the article

\section{Abstract}

\section{Introduction}

Trigger finger (TF) is a common cause of hand pain, swelling, and limited motion. It is common in women and in the thumb. Diabetes mellitus (DM) increases the risk of TF. Individuals with DM who develop TF are resistant to both medical and surgical interventions. The aim of this study is to compare the outcomes of percutaneous trigger release in diabetic and nondiabetic patients.

\section{Methods}

Fifty diabetic and 50 non-diabetic patients with a clinical diagnosis of TF were included after informed consent. Percutaneous trigger release was performed in all of them. Follow-ups for pain and/or neurovascular complications were taken after one week, one month, and six months. Data were entered and analyzed using SPSS v. 22 (IBM Corp., Armonk, NY, US).

\section{Results}

In the diabetic group, $86 \%$ of patients had TF of grade III or above and in the non-diabetic group, $76 \%$ of patients had TF of grade III or above. At the one-week follow-up, $79.2 \%$ diabetic patients still had mild to severe pain and $60.4 \%$ non-diabetic patients had mild to severe pain. By one month, $40 \%$ patients in the diabetic group still reported mild to moderate pain, however, all patients in the non-diabetic group reported no pain. By six months, nine (20\%) diabetic patients reported mild pain. There was no incidence of infection or neurovascular damage at any follow-up in the non-diabetic group, and in the diabetic group, $4.2 \%$ of patients had an infection on the one-week follow-up.

Received 04/19/2019

Review began $04 / 24 / 2019$

Review ended 04/29/2019

Published 05/02/2019

(C) Copyright 2019

Siddiqui et al. This is an open access article distributed under the terms of the Creative Commons Attribution License CC-BY 3.0., which permits unrestricted use, distribution, and reproduction in any medium, provided the original author and source are credited.

\section{Conclusion}

Percutaneous trigger finger release is a safe, reliable, time-saving, and cost-effective procedure for the management of trigger finger in both diabetic and non-diabetic patients.

Categories: Orthopedics

Keywords: percutaneous finger release, hand surgery, stenosing tenosynovitis, orthopedics, surgical complications, trigger finger, diabetes, outcome, trigger digit, complications

\section{Introduction}


Trigger finger (TF) or stenosing tenosynovitis is frequently witnessed in general practice. It is a common cause of swelling, pain, limited range of motion, and disability of the hand. TF is common in middle-aged, healthy women. It is most common in the flexor tendons of the thumb, however, it may occur in any digit [1]. The underlying triggering mechanism is induced by the thickening of the A1 pulley, which causes the entrapment of the flexor tendon [2]. The incidence of TF is 28 cases per 100000 population per annum, with a lifetime risk of $2.6 \%$ in the general population [3].

Primary TF is idiopathic and more common than secondary TF, which is common in chronic medical conditions such as gouty and rheumatoid arthritis, kidney diseases, and diabetes mellitus (DM) [1]. The lifetime risk of TF in patients with diabetes mellitus (DM) is 10\% [4].

TF presents with popping or painful catching of the flexor tendons when flexing or extending the affected digit. As TF progresses, the digit might become locked in flexion and may need passive or active correction for full range of motion. Over time, patient reluctance due to pain and consequent guarding restricts tendon motion and may secondarily lead to fixed deformity at the proximal interphalangeal (PIP) joint in the form of contractures [5]. There are various modalities for the management of trigger finger. These include local corticosteroid injections, splintage, hydrotherapy, analgesics, and percutaneous release. Open surgery is only recommended when all of these fail [5]. Percutaneous release of the triggering finger has shown promising results. It provides earlier functional recovery and high patient satisfaction [6], and it's a rapid and cost-effective procedure [7].

Elsayed, in his study, reported $97 \%$ of cases with excellent to good results and only one failure. There was no incidence of infection or nerve or tendon injury [8]. Similarly, Ragoowansi et al. also reported excellent to good results in $94 \%$ of cases managed with percutaneous release of trigger finger [9]. In a study with comparison of short and long-term outcomes in patients with and without DM, pain in the short term was equally common in both groups, and in the long term, pain was more common in the DM group [10]. The aim of this study is to compare the functional outcome in diabetic and non-diabetic patients with trigger finger managed with percutaneous release.

\section{Materials And Methods}

It was a prospective observational study conducted at Dr. Ruth Pfau Hospital, Karachi, for six months from May 1 to November 30, 2017. Data were collected using a self-structured proforma. Patients were recruited from the orthopedic consulting clinics based on a clinical diagnosis of trigger finger, with symptoms including pain, catching, and stiffness of the affected digit. The purpose, procedure, risks, and benefits of the study were explained to the patients and formal written consent was taken. Patients who refused to consent for the procedure, patients who presented with recurrent trigger finger on the same/another digit, and patients who were on anticoagulants were excluded from the study.

Triggering was classified into four grades according to severity (Modified Quinnell Grading System). In grade I, there is pain and tenderness over the A1 pulley with no entrapment or catching during the examination. In grade 2 , there is a visible entrapment but the patient is able to extend the finger actively. In grade 3, entrapment needs passive extension (grade 3A) or causes the inability to actively flex the finger (grade 3B). In grade 4 , entrapment causes fixed flexion contracture of the finger [1].

Percutaneous trigger release was performed with local anesthesia using $1.5-3 \mathrm{cc}$ of $2 \%$ xylocaine and the A1 pulley was released using a 19-gauge needle based on Eastwood's technique [11]. Adhesive dressings were applied and the patients were allowed to immediately resume their daily activities. Icing packs were advised for two-three days post-procedure. 


\section{Cureus}

Patients were followed up after one week, the second follow-up was after one month of the procedure, and the third follow-up was after six months of the procedure.

At the start of the study, 50 patients were recruited for the procedure in both the diabetic and non-diabetic groups. In the diabetic group, two patients were lost on the first follow-up (after one week) and another three patients were lost on the second follow-up visit (after one month). In the non-diabetic group, seven patients were lost on the first follow-up (after one week) and another four patients were lost on the second follow-up visit (after one month). No other patients were lost at the six-month follow-up.

Pain was assessed on each follow-up visit using the visual analog scale (VAS) [12]. It assesses pain on a 10-item visual scale, where 0 is no pain, 1-2 is mild pain, 3-6 is moderate pain, and 710 is severe pain. The complications of the procedure, including neurovascular block and local infection, were recorded on each follow-up visit.

Data were entered and analyzed using SPSS v. 22 (IBM Corp., Armonk, NY, US). Frequency and percentages were calculated for categorical data and mean and standard deviation (SD) were calculated for continuous variables.

\section{Results}

There were more women in the diabetic group (50\% vs. $48 \%$ ) and more men in the non-diabetic group (76\% vs. 24\%). The mean age of diabetic patients was more than that of non-diabetic patients. In the diabetic group, 56\% reported a history of trauma and $82 \%$ had HbA1c more than $7 \%$. The demographic and clinical characteristics of diabetic and non-diabetic patients, at baseline, are compared in Table 1.

\section{Patient characteristics}

\section{Gender}

Male

Female

Age

$18-45$ years

$>45$ years

Mean \pm SD

Trauma history

Yes

No

$22(44 \%)$

$11(22 \%)$

$<5$ years

$39(78 \%)$

$>5$ years

\section{Frequency $(\%)$}

Diabetics $(n=50)$ Non-diabetics $(n=50)$

$38(76 \%)$

$12(24 \%)$

$38.17 \pm 8.87$ 


\section{Cureus}

Mean \pm SD

$6.47 \pm 3.55$

$\mathrm{HbA} 1 \mathrm{c}$

$<7 \%$

$>7 \%$

Mean \pm SD

Dominant hand

Right

Left

Hand involved

Right

Left

Digits involved
Thumb

Index

Middle

Ring
$9(18 \%)$

$41(82 \%)$

$8.57 \pm 1.78$

$46(92 \%)$

$4(8 \%)$

$9(12 \%)$

$20(40 \%)$

$30(60 \%)$

$21(42 \%)$

$27(54 \%)$

$23(46 \%)$

$18(36 \%)$

$3(6 \%)$

$6(12 \%)$

\section{TABLE 1: Baseline demographic and clinical characteristics of diabetic and non-}

\section{diabetic patients}

Abbreviations: SD, standard deviation

Disease assessment, pain, and other complications at each visit are shown in Table 2. In the diabetic group, there were $43 / 50$ (86\%) patients who had TF of grade III or above and in the non-diabetic group, 38/50 (76\%) patients had TF of grade III or above. At the one-week followup, 38/48 (79.2\%) diabetic patients still had mild to severe pain and 26/43 (60.4\%) non-diabetic patients had mild to severe pain. By one month, 18/45 (40\%) patients in the diabetic group still reported mild to moderate pain, however, all patients in the non-diabetic group reported no pain. There was no incidence of infection or neurovascular damage at any follow-up in the nondiabetic group and in the diabetic group, only $2 / 48$ (4.2\%) patients had an infection on the oneweek follow-up (Table 2).

\begin{tabular}{|c|c|c|c|c|c|c|c|c|}
\hline \multirow{2}{*}{ Assessment of outcome } & \multicolumn{2}{|c|}{$\begin{array}{l}\text { Day } 0 \text { (before } \\
\text { procedure) }\end{array}$} & \multicolumn{2}{|c|}{$\begin{array}{l}\text { One week of } \\
\text { procedure }\end{array}$} & \multicolumn{2}{|c|}{$\begin{array}{l}\text { One month of } \\
\text { procedure }\end{array}$} & \multicolumn{2}{|c|}{$\begin{array}{l}\text { Six month of } \\
\text { procedure }\end{array}$} \\
\hline & $\begin{array}{l}\text { Diabetics } \\
(n=50)\end{array}$ & $\begin{array}{l}\text { Non- } \\
\text { diabetics } \\
(n=50)\end{array}$ & $\begin{array}{l}\text { Diabetics } \\
(n=48)\end{array}$ & $\begin{array}{l}\text { Non- } \\
\text { diabetics } \\
(n=43)\end{array}$ & $\begin{array}{l}\text { Diabetics } \\
(n=45)\end{array}$ & $\begin{array}{l}\text { Non- } \\
\text { diabetics } \\
(n=39)\end{array}$ & $\begin{array}{l}\text { Diabetics } \\
(n=45)\end{array}$ & $\begin{array}{l}\text { Non- } \\
\text { diabetics } \\
(n=39)\end{array}$ \\
\hline
\end{tabular}




\section{Cureus}

Modified Quinnell System for Trigger Finger grading

\begin{tabular}{|c|c|c|c|c|c|c|c|c|}
\hline $\begin{array}{l}\text { Grade I Normal } \\
\text { movement, No Pain }\end{array}$ & $3(6 \%)$ & $4(8 \%)$ & $\begin{array}{l}7 \\
(14.5 \%)\end{array}$ & $\begin{array}{l}16 \\
(37.2 \%)\end{array}$ & $\begin{array}{l}17 \\
(37.8 \%)\end{array}$ & $\begin{array}{l}28 \\
(71.8 \%)\end{array}$ & $\begin{array}{l}39 \\
(86.7 \%)\end{array}$ & $\begin{array}{l}38 \\
(97.5 \%)\end{array}$ \\
\hline $\begin{array}{l}\text { Grade II Normal } \\
\text { movement, occasional } \\
\text { pain }\end{array}$ & $4(8 \%)$ & $8(16 \%)$ & $\begin{array}{l}16 \\
(33.3 \%)\end{array}$ & $\begin{array}{l}14 \\
(32.5 \%)\end{array}$ & $\begin{array}{l}23 \\
(51.1 \%)\end{array}$ & $\begin{array}{l}11 \\
(28.2 \%)\end{array}$ & $6(13.3)$ & $1(2.5 \%)$ \\
\hline $\begin{array}{l}\text { Grade III Uneven } \\
\text { movement }\end{array}$ & $14(28 \%)$ & $19(38 \%)$ & $\begin{array}{l}23 \\
(47.9 \%)\end{array}$ & $\begin{array}{l}13 \\
(30.2 \%)\end{array}$ & $\begin{array}{l}5 \\
(11.1 \%)\end{array}$ & -- & -- & -- \\
\hline $\begin{array}{l}\text { Grade IV Intermittent } \\
\text { locking, actively } \\
\text { correctable }\end{array}$ & $18(36 \%)$ & $13(26 \%)$ & $2(4.2 \%)$ & -- & -- & -- & -- & -- \\
\hline $\begin{array}{l}\text { Grade V Locking only } \\
\text { passively correctable }\end{array}$ & $11(22 \%)$ & $6(12 \%)$ & -- & -- & -- & -- & -- & -- \\
\hline \multicolumn{9}{|c|}{ VAS Scale for pain assessment } \\
\hline No pain & $5(10 \%)$ & $5(10 \%)$ & $\begin{array}{l}10 \\
(20.8 \%)\end{array}$ & $\begin{array}{l}17 \\
(39.5 \%)\end{array}$ & $27(60 \%)$ & $\begin{array}{l}39 \\
(100 \%)\end{array}$ & $\begin{array}{l}36 \\
(80.0 \%)\end{array}$ & $\begin{array}{l}39 \\
(100 \%)\end{array}$ \\
\hline Mild pain & $11(22 \%)$ & $9(18 \%)$ & $\begin{array}{l}20 \\
(41.6 \%)\end{array}$ & $\begin{array}{l}20 \\
(46.5 \%)\end{array}$ & $\begin{array}{l}15 \\
(33.3 \%)\end{array}$ & -- & $\begin{array}{l}9 \\
(20.0 \%)\end{array}$ & -- \\
\hline Moderate pain & $24(48 \%)$ & $20(40 \%)$ & $11(23 \%)$ & $6(13.9 \%)$ & $3(6.7 \%)$ & -- & -- & -- \\
\hline Severe pain & $10(20 \%)$ & $16(32 \%)$ & $\begin{array}{l}7 \\
(14.5 \%)\end{array}$ & -- & -- & -- & -- & -- \\
\hline \multicolumn{9}{|c|}{ Complications of the procedure } \\
\hline $\begin{array}{l}\text { Superficial wound } \\
\text { Infection }\end{array}$ & -- & -- & $2(4.2 \%)$ & -- & -- & -- & -- & -- \\
\hline Neurapraxia & -- & -- & -- & -- & -- & -- & -- & -- \\
\hline Vascular injury & -- & -- & -- & -- & -- & -- & -- & -- \\
\hline Others & -- & -- & -- & -- & -- & -- & -- & -- \\
\hline
\end{tabular}

\section{TABLE 2: Severity of TF, pain, and other complications in diabetic and non-diabetic} patients

Abbreviations: VAS, Visual Analogue Scale.

Infection in both patients of the diabetic group was managed successfully with empirical antibiotic agents. None of the patients in either group presented with a recurrent trigger during the follow-up period and the procedure did not fail in any patient; a re-procedure was not required. 


\section{Cureus}

The preoperative flexed position of the involved digit is shown in Figure 1.

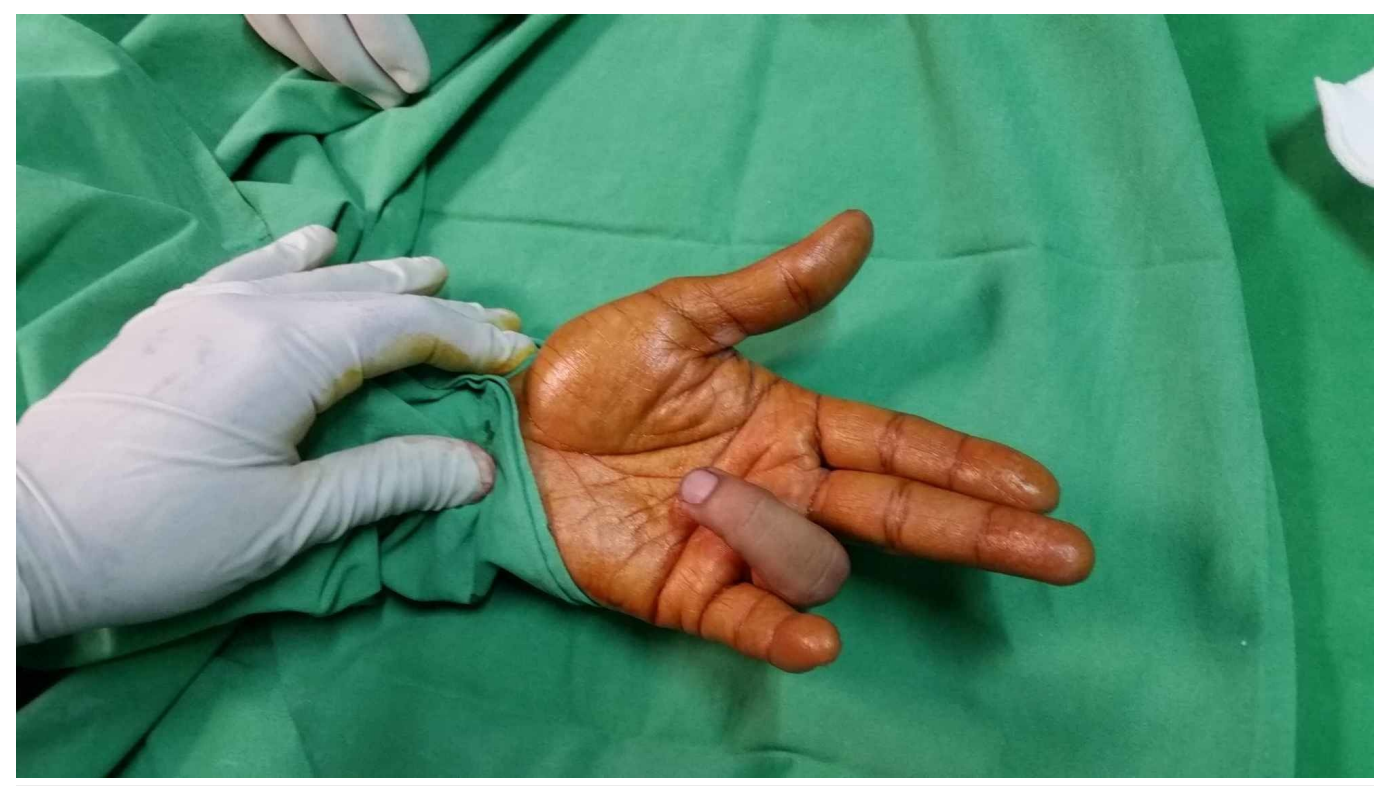

FIGURE 1: Preoperative

The procedure is shown in Figure 2.

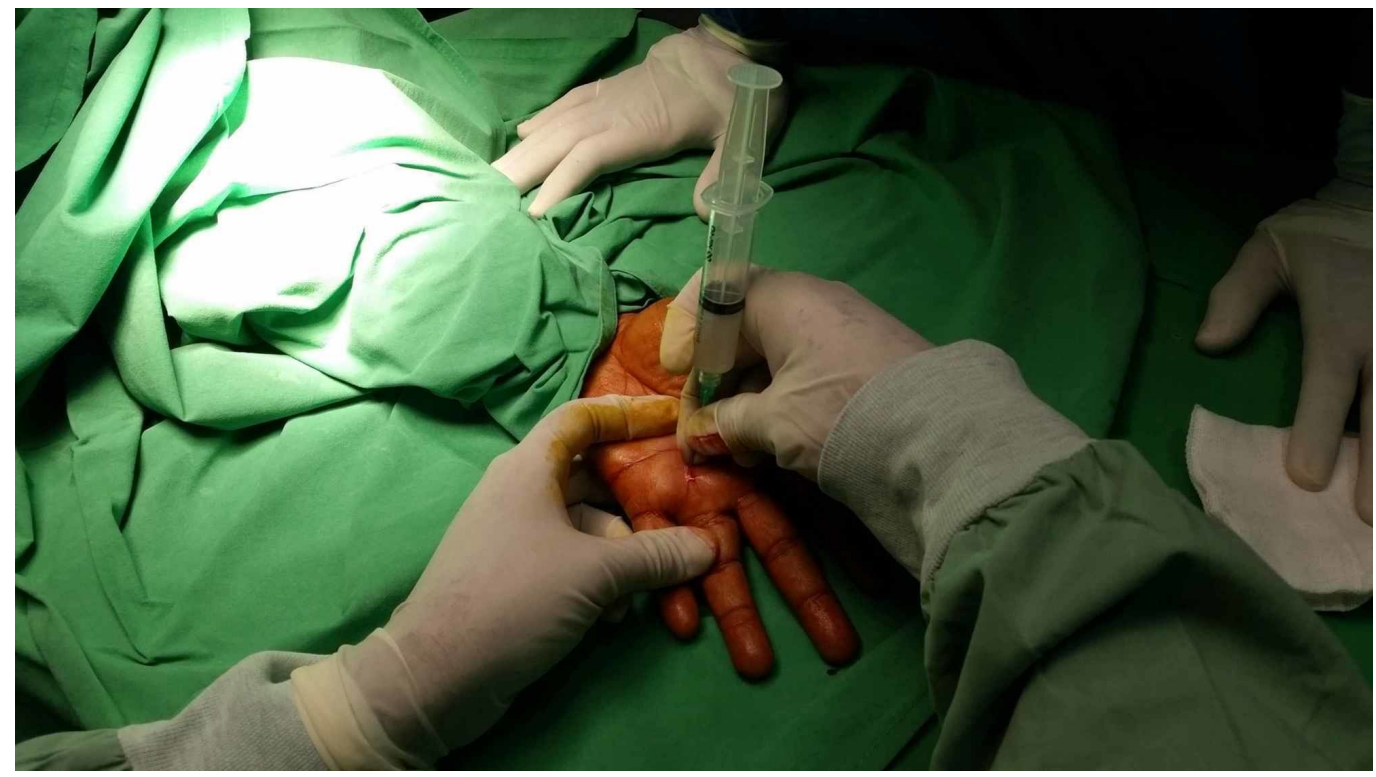

FIGURE 2: Percutaneous trigger digit release

\section{Discussion}

In light of the findings of this study, percutaneous release of trigger finger is a safe and reliable procedure. Pain was a common complication, which was more common in diabetic individuals. However, no other serious complication, including neurovascular damage, was reported.

This study has contributed to the safety and reliability of percutaneous release in trigger finger 
in both diabetic and non-diabetic patients. However, this study has its limitations. Patients with recurrent TF were excluded; they might have had a worse outcome. It was a single-center study with a smaller sample and a short study duration. Patients were followed for six months only, hence, long-term complications/outcomes cannot be assessed.

As discussed earlier, individuals with diabetes mellitus have a higher frequency of TF. DM has been established as a bad prognostic factor for medical and surgical interventions in trigger finger [13-14]. Percutaneous release has been reported to be a safe procedure with no to minimum neurovascular damage and very few incidences of infection. In a study with the longterm follow-up of patients undergoing percutaneous release of TF, no long-term complication was seen, other than pain [1]. Similarly, in another study from Pakistan, the three-month outcome for the percutaneous release of TF was satisfactory in 90\% patients and recurrence was seen in none [5].

Huang et al. conducted a longitudinal study with a large sample size to compare the outcome of percutaneous release of TF in diabetic and non-diabetic persons [10]. Short-term pain was seen in $5 \%$ of diabetic and non-diabetic digits each. In the long-term, pain was seen in $25 \%$ of the digits of diabetic patients and in $14 \%$ of the digits of non-diabetic patients $(p=0.058)$. They also reported recurrent triggering in $15 \%$ of the diabetic patients and only in $5 \%$ of the non-diabetic patients $(p=0.013)$ [10]. In comparison, by the end of one month, $40 \%$ diabetic patients in our study reported pain as compared to none in the non-diabetic group. However, we did not find any case of recurrence, maybe because our patients were not followed for a longer time period. Eastwood et al. followed their patients for a mean of 13 months and did not observe any recurrence [11].

In another recent study with 39 patients of Grade 3 trigger fingers managed with percutaneous release, hypoesthesia was reported in seven patients at the end of the first postoperative year and in two patients at the end of the third postoperative year. At the end of the first postop year, one case of tendon rupture was also reported. Recurrence was seen in five patients at the end of the first postop year and in nine patients at the end of the third postop year. There were painful scars in two patients by the end of the first year and in none by the third year postop. They did not report any incidence of superficial wound infection [15]. To the best of our knowledge, this is the only study that reported hypoaesthesia as a postop complication in percutaneous trigger finger release.

\section{Conclusions}

Percutaneous trigger finger release is a safe, reliable, time-saving, and cost-effective procedure for the management of trigger finger in both diabetic and non-diabetic patients. Pain and superficial wounds remain a more common complication in diabetic patients; however, neurovascular complications were not seen.

\section{Additional Information \\ Disclosures}

Human subjects: Consent was obtained by all participants in this study. Dr Ruth Pfau Hospital issued approval 119/10/16. Animal subjects: All authors have confirmed that this study did not involve animal subjects or tissue. Conflicts of interest: In compliance with the ICMJE uniform disclosure form, all authors declare the following: Payment/services info: All authors have declared that no financial support was received from any organization for the submitted work. Financial relationships: All authors have declared that they have no financial relationships at present or within the previous three years with any organizations that might have an interest in the submitted work. Other relationships: All authors have declared that there are no other 
relationships or activities that could appear to have influenced the submitted work.

\section{References}

1. Saremi H, Hakhamaneshi E, Rabiei MA: Percutaneous release of trigger fingers: comparing multiple digits with single digit involvement. Arch Bone Jt Surg. 2016, 4:224-227.

2. Sampson SP, Badalamente MA, Hurst LC, Seidman J: Pathobiology of the human A1 pulley in trigger finger. J Hand Surg Am. 1991, 16:714-721. 10.1016/0363-5023(91)90200-U

3. Saldana M: Trigger digits: diagnosis and treatment. J Am Acad Orthop Surg. 2001, 9:246-252.

4. Fitzgerald B, Setty A, Mudgal C: Gout affecting the hand and wrist. J Am Acad Orthop Surg. 2007, 15:625-635.

5. Marij Z, Aurangzeb Q, Rizwan H, Haroon R, Pervaiz M: Outpatient percutaneous release of trigger finger: a cost effective and safe procedure. Malays Orthop. 2017, 11:52-56. 10.5704/MOJ.1703.021

6. Slesarenko Y, Mallo G, Hurst L, Sampson S, Serra-Hsu F: Percutaneous release of A1 pulley. Tech Hand Up Extrem Surg. 2006, 10:54-56.

7. Kerrigan C, Stanwix M: Using evidence to minimize the cost of trigger finger care . J Hand Surg. 2009, 34:997-1005. 10.1016/j.jhsa.2009.02.029

8. Elsayed MM: Percutaneous release of trigger finger . Egypt Orthop J. 2013, 48:277-281. 10.4103/1110-1148.125836

9. Ragoowansi R, Acornley A, Khoo CT: Percutaneous trigger finger release: the 'lift-cut' technique. Br J Plast Surg. 2005, 58:817-821. 10.1016/j.bjps.2005.04.003

10. Huang HK, Wang JP, Wang ST, Liu YA, Huang YC, Liu CL: Outcomes and complications after percutaneous release for trigger digits in diabetic and non-diabetic patients. J Hand Surg. 2015, 40:735-739. 10.1177/1753193415590389

11. Eastwood DM, Gupta KJ, Johnson DP: Percutaneous release of the trigger finger: an office procedure. J Hand Surg. 1992, 17:114-117. 10.1016/0363-5023(92)90125-9

12. Delgado DA, Lambert BS, Boutris N, McCulloch P, Robbins A, Moreno M, Harris J: Validation of digital visual analog scale pain scoring with a traditional paper-based visual analog scale in adults. J Am Acad Orthop Surg Glob Res Rev. 2018, 2:e088. 10.5435/JAAOSGlobal-D-17-00088

13. Sheikh E, Peters JD, Sayde W, Maltenfort M, Leinberry C: A prospective randomized trial comparing the effectiveness of one versus two (staged) corticosteroid injections for the treatment of stenosing tenosynovitis. Hand. 2014, 9:340-345. 10.1007/s11552-014-9603-4

14. Baumgarten KM, Gerlach D, Boyer MI: Corticosteroid injection in diabetic patients with trigger finger. A prospective, randomized, controlled double-blinded study. J Bone Joint Surg Am. 2007, 89:2604-2611. 10.2106/JBJS.G.00230

15. Aksoy A, Sir E: Complications of percutaneous release of the trigger finger . Cureus. 2019, 11:4132. 10.7759/cureus.4132 